\title{
Editorial:
}

\section{Preventing Cardio-renal Syndrome Rather than Treating It: Could Statins Play A Role?}

\author{
Vasilios G. Athyros ${ }^{1, *}$, Niki Katsiki ${ }^{2}$, Konstantinos Tziomalos ${ }^{3}$ and Asterios Karagiannis ${ }^{1}$ \\ ${ }^{I}$ Second Propedeutic Department of Internal Medicine, Medical School, Aristotle University of Thessaloniki, Hippocration \\ Hospital, Thessaloniki, Greece \\ ${ }^{2}$ Department of Clinical Biochemistry (Vascular Disease Prevention Clinic) and Department of Surgery, Royal Free \\ Campus, University College London Medical School, University College London (UCL), London, UK \\ ${ }^{3}$ First Propedeutic Department of Internal Medicine, Medical School, Aristotle University of Thessaloniki, AHEPA \\ Hospital, Thessaloniki, Greece
}

Keywords: Chronic kidney disease, coronary heart disease, heart failure, cardiorenal syndrome, statins, dyslipidaemia.

Cardiorenal syndrome (CRS) is the umbrella term used to describe clinical conditions in which renal dysfunction accompanies cardiac failure or cardiac dysfunction accompanies renal failure [1,2]. There are 5 types of CRS (Table 1). The rising prevalence of chronic kidney disease (CKD) and heart failure (HF), contributed to the increase of the incidence of CRS, which was further increased by the improved survival of patient with HF, CKD or both [3, 4]. The heterogeneous and complex pathophysiology of CRS makes effective patient management difficult. Established therapeutic strategies, such as diuretics, are often associated with resistance and limited clinical success $[3,5]$.

Fabian et al. [6] provide useful data about CRS. The percentage of patients with the syndrome is relatively high among patients admitted in an Internal Medicine Ward ( 1 in 7 patients). In CRS, HF and CKD shared a substantial number of risk factors [6], such as old age, arterial hypertension, diabetes mellitus (DM), and history of cardiovascular disease (CVD) [6].

Despite the fact that Fabian et al. do not report mortality rates they support that "women with glomerular filtration rate (GFR) $30-44 \mathrm{ml} / \mathrm{min} / 1.73 \mathrm{~m}^{2}$ and men with GFR $30-50$ $\mathrm{ml} / \mathrm{min} / 1.73 \mathrm{~m}^{2}$ but without history of CVD had a hazard ratio for CVD of 1.51 that increased to 2.39 in those with CVD history. Worsening of renal function is also an independent predictor of mortality in acute decompensated heart failure (ADHF)." Moreover, it has been established that individuals with CKD are more likely to die of CVD than to develop kidney failure [7]. Thus, given the poor prognosis of CRS [3,5] Fabian et al. suggest that prevention is a priority [8].

\footnotetext{
*Address correspondence to this author at the Second Propedeutic Department of Internal Medicine, Medical School, Aristotle University of Thessaloniki, Hippocration Hospital, Marmara 13, 55132, Thessaloniki, Greece; Tel: +30 2310 454237; Fax: +30 2310445220 ;

E-mail: athyros@med.auth.gr
}

Some of the measures of CRS prevention are focused, according to CRS type, on preventing decompensation of stable HF, optimal medical and device treatment of HF with blood pressure and volume control, prevention of acute renal injury (AKI), attenuating the progression of $\mathrm{CKD}$, and treatment of the underlying systemic disease to reduce endorgan injury [3,5].

CRS is a haemodynamic derangement ranging from acute pulmonary oedema, with hypertension through severe peripheral fluid overload, to cardiogenic shock and hypotension [9]. However, its pathophysiology is much more complex than simply reduced cardiac output or renal dysfunction. Factors such as nitric oxide, prostaglandin, natriuretic peptides, and endothelin may mediate renal perfusion independently of cardiac haemodynamics and vice versa [10].

There are some "established" measures for the prevention or the treatment of CRS. One of these is renin-angiotensinaldosterone system (RAAS) blockade [5]. Many trials confirmed the benefits of angiotensin enzyme inhibitors (ACEI), such as Studies of Left Ventricular Dysfunction (SOLVD), in the treatment of HF [11]. However, SOLVD excluded patients with serum creatinine concentrations $>2.0 \mathrm{mg} / \mathrm{dL}$. The Cooperative North Scandinavian Enalapril Survival Study (CONSENSUS) [12] in patients with severe HF, included patients with renal impairment, but only if their serum creatinine concentrations were $<3.4 \mathrm{mg} / \mathrm{dl}$. Although only a minority of patients in CONSENSUS had creatinine levels $>2.0 \mathrm{mg} / \mathrm{dL}$, this subgroup showed evidence of improved outcomes when treated with an ACEI [12]. Some of those experienced a serum creatinine increased by $30 \%$ or greater with enalapril [12]. However, creatinine tended to stabilize and in many patients improved throughout the study. Therefore, it has been suggested that RAAS blockade may be carefully titrated provided that serum creatinine does not continue to rise beyond $30 \%$ and potassium is constantly $<5.0 \mathrm{mmol} / \mathrm{L}$ [13]. ACEI therapy in patients with baseline renal insufficiency is associated with significant long-term 
Table 1. Types of Cardiorenal Syndrome

\begin{tabular}{|c|c|c|}
\hline Type of Cardiorenal Syndrome & Definition & Primary Event \\
\hline Acute cardio-renal (type 1) (20-25\%) & $\begin{array}{l}\text { Acute worsening of heart function (AHF-ACS) } \\
\text { leading to kidney injury and/or dysfunction }\end{array}$ & $\begin{array}{l}\text { Acute heart failure (AHF) or acute coronary } \\
\text { syndrome (ACS) or cardiogenic shock }\end{array}$ \\
\hline Chronic cardio-renal (type 2) (30-45\%) & $\begin{array}{l}\text { Chronic abnormalities in heart } \\
\text { function (CHF-CHD) leading to } \\
\text { kidney injury or dysfunction }\end{array}$ & $\begin{array}{l}\text { Chronic heart disease (systolic and/or } \\
\text { diastolic dysfunction, chronic } \\
\text { abnormalities in cardiac function, } \\
\text { cardiomyopathy) }\end{array}$ \\
\hline Acute reno-cardiac (type 3) (30-35\%) & $\begin{array}{l}\text { Acute worsening of kidney function leading to } \\
\text { heart injury and/or dysfunction }\end{array}$ & Acute kidney injuring (AKI) \\
\hline Chronic reno-cardiac (type 4) (45-50\%) & $\begin{array}{l}\text { Chronic kidney disease (CKD) leading to heart } \\
\text { injury, disease and/or dysfunction }\end{array}$ & CKD \\
\hline Secondary cardio-renal (type 5) & Systemic condition causing cardiac and renal dys- & Systemic disease (septic shock, diabetes, MetS, \\
\hline
\end{tabular}

$\mathrm{AHF}=$ Acute heart failure, $\mathrm{ACS}=$ acute coronary syndrome, $\mathrm{AKI}=$ acute kidney injury, $\mathrm{CKD}=$ chronic kidney disease, MetS $=$ Metabolic syndrome, $\mathrm{NAFLD}=$ non alcoholic fatty liver disease.

benefits [14], and unless contraindicated, should be routinely used [5]. Most patients who are already on an ACEI and develop renal insufficiency during hospitalization for $\mathrm{HF}$ decompensation should not have their ACEI stopped. In general, ACEI use is not associated with worsening renal function in these patients [15]. However, clinical judgment should be used in patients with cardiogenic shock or acute renal failure [14].

Blockade of the sympathetic system with beta-blockers is another important strategy for patients with congestive HF or CHD [13]. In general, these drugs should not adversely affect kidney function. Certain beta-blockers may be relatively contraindicated in CKD because of metabolism by the kidney, such as atenolol, nadolol or sotalol [16]. Carvedilol has been demonstrated to have favourable effects on kidney function in some CRS patients, and may have a benefit over older beta-blockers [17].

Both congestive HF and CKD are associated with anaemia, the latter of which is commonly treated with erythropoiesis-stimulating agents [18], and there is interest in using erythropoiesis-stimulating agents in HF patients [19]. However, other studies did not find significant improvement in a variety of important clinical parameters [20]. Moreover, the Trial to Reduce Cardiovascular Events with Aranesp Therapy (TREAT) [21] reported that patients with a poor response to darbepoetin alfa, compared with those with a better response, had higher rates of the composite CVD end point [adjusted hazard ratio (HR), 1.31; 95\% confidence interval [CI], 1.09 to 1.59 ) or death (adjusted HR, 1.41; 95\% CI, 1.12 to 1.78 ), as doses were increased to attain target haemoglobin levels. These findings raise concern about current strategies for treating anaemia in patients with CKD [21].

However, it seems that there is a treatment that potentially improves both cardiac and renal function and practically remains unused in the effort to prevent CRS: effective statin treatment with a specific compound at specific doses [22].

It was shown in a post hoc analysis of the Treating to New Targets $($ TNT) study $(n=10,001)$ that $80 \mathrm{mg} /$ day of atorvastatin compared with the $10 \mathrm{mg} /$ day dose, in patients with stable coronary heart disease (CHD) significantly reduces hospitalizations for HF [23]. However, this benefit was mainly shaped by CHD patients with a history of HF (7.8\% of study population) [23]. In this subgroup the incidence of hospitalizations was substantially less in the 80 $\mathrm{mg}$ /day group than those with a $10 \mathrm{mg}$ /day group [17.3 vs $10.6 \%$ in the 10 - and $80-\mathrm{mg}$ arms, respectively (HR 0.59 ; 95\% CI 0.4 to $0.88 ; \mathrm{P}=0.009)$ ] [23]. Similar were the results of the GREek Atorvastatin and Coronary-heart-disease Evaluation (GREACE) study [24] that we reported 5 years earlier than TNT. A post hoc analysis of the Scandinavian Simvastatin Survival Study (4S) in 1997 [25] showed that mortality was $31.9 \%$ in the placebo group and $25.5 \%$ in the simvastatin group among patients who developed HF. These 
were substantially higher than the mortality rates of non-HF patients (9.2 and $6.6 \%$, respectively), however, the reduction in mortality and hospitalizations were comparable among HF and non-HF patients [25]. Still, this is the heart end of the CRS. The issue is to cover both the heart and kidney.

Early CKD (up to stage 3 ; the stages of CKD are reported in Table 2) could be slowed down [26] or even reversed by statins which on the other hand substantially reduce CVD events [22, 27-30]. Uncontrolled dyslipidaemia induces a renal function impairment that ranges from 1 to 12 $\mathrm{ml} / \mathrm{min} / 1.73 \mathrm{~m}^{2}$ per year, particularly in the presence of diabetes (DM) or arterial hypertension [27,29]. A large study with $40 \mathrm{mg} / \mathrm{day}$ of simvastatin (the Heart Protection Study, $\mathrm{n}=20,000$ ) [31] and a joint analysis of pravastatin trials [32] showed that these statins reduce the rate of the (expected with age and CVD risk factors) kidney function decline in patients with or at risk of CVD. In the GREACE study, we showed for the first time that atorvastatin treatment significantly increases eGFR. In contrast, eGFR was reduced in untreated patients with CHD with or without metabolic syndrome (MetS) or DM [33-35]. This improvement of renal function was clinically relevant and associated with substantially reduced CVD events [33]. With every 5\% in eGFR increase there was a reduction of $16 \%$ in clinical vascular events, after multiple regression analysis adjusting for major covariates [33]. Thus, with a $10 \%$ increase of eGFR in stage 2 and 3 CKD patients in GREACE we recorded a $32 \%$ further (independent of LDL-C) reduction in clinical events [33]. A substantial benefit of atorvastatin treatment was also seen in the large TNT trial $(\mathrm{n}=10,001$ patients with stable CHD) [36,37]. In stage 3 CKD TNT patients, the increase in eGFR was significantly greater with atorvastatin $80 \mathrm{mg}$ /day than with $10 \mathrm{mg} /$ day ( 9.9 vs $6.6 \%$, respectively; $\mathrm{p}<0.005$ ) [36]. In patients with stage 3 CKD $(n=3,107)$ the HR for CVD events was $31.9 \%$ higher than those without CKD ( $\mathrm{n}=$ 6,549), regardless of atorvastatin dose [36]. Nevertheless, compared with atorvastatin $10 \mathrm{mg} / \mathrm{day}$, the $80 \mathrm{mg} /$ day dose reduced the relative risk of major CVD events significantly more in those with CKD (by 32 vs $15 \%$ in those with normal renal function) [37] This reduction shaped the overall TNT outcome and was identical with the one we recorded in GREACE [33]. In the Collaborative Atorvastatin Diabetes Study (CARDS) [38], a randomized placebo-controlled trial that included 2,838 patients with type $2 \mathrm{DM}$ and free of CVD at baseline, $34 \%$ of the patients had stage 3 CKD (eGFR of $30-59 \mathrm{ml} / \mathrm{min} / 1.73 \mathrm{~m}^{2}$-Table 2). In these patients atorvastatin $10 \mathrm{mg} / \mathrm{day}$ was associated with a moderate improvement in the annual change in eGFR $(\mathrm{p}=0.01)$. This was accompanied by a substantial reduction in major CVD events (total mortality plus non-fatal myocardial infarction: $42 \%)$ and stroke (-61\%) [38], compared with placebo.

In GREACE, TNT and CARDS, the control of other CVD risk factors (except dyslipidaemia) was similar in the atorvastatin and placebo (or usual care for GREACE) groups; therefore the improvement in renal function and the clinical benefit in terms of CVD event reduction is attributed to atorvastatin use. This stage 3 CKD patient group is a substantial part of secondary prevention patients (32 to $34 \%$ in all 3 of the studies above) and benefited most from lipidlowering in all 3 studies. In the above studies in patients effectively treated with statins there were less acute coronary events (less ground for type 1 CRS), less cases with congestive HF (less ground for type 2 CRS) and fewer cases with CKD, because statin treatment halted the evolution of kidney impairment or even reversed it. Thus, there was less ground for type 4 CRS and if CKD is the perfect substrate for acute kidney impairment after haemodynamic derangement, less ground for type 3 CRS. Even type 5 CRS could be prevented, at least in part, with statin treatment. There is a positive impact of managing atherogenic dyslipidaemia on CVD outcome across all stages of diabetic nephropathy [29], MetS [39], non alcoholic fatty liver disease (NAFLD) [40], or systemic autoimmune diseases (SAD) [41]. CVD is the leading cause of morbidity and mortality in patients with SADs [42]. Patients with systemic lupus erythematosus (SLE) are 5-6 times more likely to have a significant coronary event than the general population [43]. Rheumatoid arthritis (RA) is also associated with an increased CVD risk resulting in early mortality and excess morbidity [42-44]. However these diseases also affect renal function [45]. Both CVD and CKD might be effectively managed, to some extent, by statins [42] Both CVD and CKD in the above diseases are related to low grade inflammation, endothelial dysfunction-low NO levels, oxidative stress, instability of atherosclerotic plaques and a pro-coagulant state related to atherosclerosis $[41,46]$. There is evidence that these factors could be controlled by the pleiotropic (cholesterol-lowering-independent) effects of statins [46]. These effects are enhanced by even a small increase in high density lipoprotein cholesterol levels [47], and are evident even in patients with mild renal impairment [48].

All the above suggest that the use of ACEI and statins might be an effective regimen to prevent a substantial num-

Table 2. Stages of Chronic Kidney Disease

\begin{tabular}{|l|c|c|}
\hline & Description & $\begin{array}{c}\text { GFR } \\
\text { ml/min/1.73m }\end{array}$ \\
\hline \hline Stage 1 & Kidney damage with normal or increased GFR & $\geq 90$ \\
\hline Stage 2 & Kidney damage with mildly decreased GFR & $60-89$ \\
\hline Stage 3 & Moderately decreased GFR & $30-59$ \\
\hline Stage 4 & Severely decreased GFR & $15-29$ \\
\hline Stage 5 & Kidney failure & $<15$ or dialysis \\
\hline
\end{tabular}

$\mathrm{GFR}=$ glomerular filtration rate. 
ber of CRS cases in high risk patients and improve survival and quality of life in these people. There are data suggesting that combined use of a statin plus an ACEI improves clinical outcome more than a statin alone and considerably more than an ACEI alone [30]. After all, recent guidelines suggest that CKD is a high CVD risk situation [49,50]. This requires aggressive statin treatment.

\section{DISCLOSURE}

This editorial was written independently; no company or institution supported it financially. No professional writer was involved. The authors have given talks, attended conferences and participated in trials and advisory boards sponsored by various pharmaceutical companies.

\section{CONFLICT OF INTEREST}

There is no conflict of interest.

\section{ACKNOWLEDGEMENT}

None declared.

\section{REFERENCES}

[1] Ronco C, McCullough P, Anker SD, et al. Acute Dialysis Quality Initiative (ADQI) consensus group. Cardio-renal syndromes: report from the consensus conference of the acute dialysis quality initiative. Eur Heart J 2010; 31: 703-11.

[2] Shah BN, Greaves K. The cardiorenal syndrome: a review. Int J Nephrol 2010; 2011: 920195.

[3] Koniari K, Nikolaou M, Paraskevaidis I, Parissis J. Therapeutic options for the management of the cardiorenal syndrome. Int $\mathbf{J}$ Nephrol 2010; 2011: 194910.

[4] Parikh CR, Coca SG, Wang Y, Masoudi FA, Krumholz HM. Longterm prognosis of acute kidney injury after acute myocardial infarction. Arch Intern Med 2008; 168: 987-95.

[5] Geisberg C, Butler J. Addressing the challenges of cardiorenal syndrome. Cleve Clin J Med 2006; 73: 485-91.

[6] Fabbian F, Pala M, De Giorgi A, et al. Clinical features of cardio-renal syndrome in a cohort of consecutive patients admitted to an internal medicine ward. Open Cardiovasc Med J 2011, (in press).

[7] Shulman NB, Ford CE, Hall WD, et al. Prognostic value of serum creatinine and effect of treatment of hypertension on renal function: results from the hypertension detection and follow-up program. The Hypertension Detection and Follow-up Program Cooperative Group. Hypertension 1989; 13(suppl 5): I80-I93.

[8] McCullough PA, Haapio M, Mankad S, et al. Acute Dialysis Quality Initiative (ADQI) Consensus Group. Prevention of cardio-renal syndromes: workgroup statements from the 7th ADQI Consensus Conference. Nephrol Dial Transplant 2010; 25: 1777-84.

[9] Hunt SA, Abraham WT, Chin MH, et al. 2009 focused update incorporated into the ACC/AHA 2005 guidelines for the diagnosis and management of heart failure in adults: A report of the American College of Cardiology Foundation/American Heart Association Task Force on Practice Guidelines: Developed in collaboration with the international society for Heart and Lung Transplantation. J Am Coll Cardiol 2009; 53(15): e1-e90.

[10] Forman DE, Bulter J, Wang Y, et al. Incidence, predicators at admission and impact of worsening renal function among patients hospitalized with heart failure. J Am Coll Cardiol 2004; 43: 62-7.

[11] The SOLVD Investigators. Effect of enalapril on survival in patients with reduced left ventricular ejection fractions and congestive heart failure. N Engl J Med 1992; 325: 293-302.

[12] Ljungman S, Kjekshus J, Swedberg K. Renal function in severe congestive heart failure during treatment with enalapril (the Cooperative North Scandinavian Enalapril Survival Study [CONSENSUS] Trial). Am J Cardiol 1992; 70: 479-87.

[13] House AA, Haapio M, Lassus J, Bellomo R, Ronco C. Pharmacological management of cardiorenal syndromes. Int J Nephrol 2011; 2011: 630809.
[14] Hou FF, Zhang X, Zhang GH, et al. Efficacy and safety of benazepril for advanced chronic renal insuficiency. N Engl J Med 2006; 354: 131-40.

[15] Butler J, Forman DE, Abraham WT, et al. Relationship between heart failure treatment and development of worsening renal function among hospitalized patients. Am Heart J 2004; 147: 331-8.

[16] Yorgun H, Deniz A, Aytemir K. Cardiogenic shock secondary to combination of diltiazem and sotalol. Intern Med J 2008; 38: 221-2.

[17] Bakris GL, Hart P, Ritz E. Beta blockers in the management of chronic kidney disease. Kidney Int 2006; 70: 1905-13.

[18] McCullough PA, Lepor NE. The deadly triangle of anemia, renal insufficiency, and cardiovascular disease: implications for prognosis and treatment. Rev Cardiovasc Med 2005; 6: 1-10.

[19] Pagourelias ED, Koumaras C, Kakafika AI, et al. Cardiorenal anemia syndrome: do erythropoietin and iron therapy have a place in the treatment of heart failure? Angiology 2009; 60: 74-81.

[20] McCullough PA, Wolyn R, Rocher LL, Levin RN, O'Neill WW. Acute renal failure after coronary intervention: incidence, risk factors, and relationship to mortality. Am J Med 1997; 103: 368-75.

[21] Solomon SD, Uno H, Lewis EF, et al. Trial to Reduce Cardiovascular Events with Aranesp Therapy (TREAT) Investigators. Erythropoietic response and outcomes in kidney disease and type 2 diabetes. N Engl J Med 2010; 363: 1146-55.

[22] Athyros VG, Karagiannis A, Kakafika A, Elisaf M, Mikhailidis DP. Statins and renal function. Is the compound and dose making a difference? Nephrol Dial Transplant 2007; 22: 963-4.

[23] Khush KK, Waters DD, Bittner V, et al. Effect of high-dose atorvastatin on hospitalizations for heart failure: subgroup analysis of the Treating to New Targets (TNT) study. Circulation 2007; 115: 576-83.

[24] Athyros VG, Karagiannis A, Mikhailidis DP. Statins and heart failure. J Am Coll Cardiol 2010; 55: 1644-5.

[25] Kjekshus J, Pedersen TR, Olsson AG, Faergeman O, Pyörälä K. The effects of simvastatin on the incidence of heart failure in patients with coronary heart disease. J Card Fail 1997; 3: 249-54.

[26] Sandhu S, Wiebe N, Fried LF, Tonelli M. Statins for improving renal outcomes: a meta-analysis. J Am Soc Nephrol 2006; 17: 2006-16.

[27] Kalaitzidis RG, Elisaf MS. The role of statins in chronic kidney disease. Am J Nephrol 2011; 34: 195-202.

[28] Fellström B, Holdaas H, Jardine AG, et al. AURORA Study Group. Cardiovascular disease in patients with renal disease: the role of statins. Curr Med Res Opin 2009; 25: 271-85.

[29] Athyros VG, Mitsiou EK, Tziomalos K, Karagiannis A, Mikhailidis DP. Impact of managing atherogenic dyslipidemia on cardiovascular outcome across different stages of diabetic nephropathy. Expert Opin Pharmacother 2010; 11: 723-30.

[30] Athyros VG, Mikhailidis DP, Papageorgiou AA, et al. GREACE Study Collaborative Group. Effect of statins and ACE inhibitors alone and in combination on clinical outcome in patients with coronary heart disease. J Hum Hypertens 2004; 18: 781-8.

[31] Collins R, Armitage J, Parish S, et al. MRC/BHF Heart Protection Study of cholesterol-lowering with simvastatin in 5963 people with diabetes: A randomised placebo-controlled trial. Lancet 2003; 361: 2005-16.

[32] Tonelli M, Isles C, Craven T, et al. Effect of pravastatin on rate of kidney function loss in people with or at risk for coronary disease. Circulation 2005; 112: 171-8.

[33] Athyros VG, Mikhailidis DP, Papageorgiou AA, et al. The effect of statins versus untreated dyslipidaemia on renal function in patients with coronary heart disease. A subgroup analysis of the Greek atorvastatin and coronary heart disease evaluation (GREACE) study. J Clin Pathol 2004; 57: 728-34.

[34] Athyros VG, Mikhailidis DP, Liberopoulos EN, et al. Effect of statin treatment on renal function and serum uric acid levels and their relation to vascular events in patients with coronary heart disease and metabolic syndrome: a subgroup analysis of the GREek Atorvastatin and Coronary heart disease Evaluation (GREACE) Study. Nephrol Dial Transplant 2007; 22: 118-27.

[35] Athyros VG, Papageorgiou AA, Elisaf M, Mikhailidis DP; GREACE Study Collaborative Group. Statins and renal function in patients with diabetes mellitus. Curr Med Res Opin 2003; 19: 615-7.

[36] Shepherd J, Kastelein JJ, Bittner V, et al. Treating to New Targets Investigators. Effect of intensive lipid lowering with atorvastatin on renal function in patients with coronary heart disease: the Treating 
to New Targets (TNT) study. Clin J Am Soc Nephrol 2007; 2: 1131-9.

[37] Shepherd J, Kastelein JJ, Bittner V, et al. Intensive lipid lowering with atorvastatin in patients with coronary heart disease and chronic kidney disease: the TNT (Treating to New Targets) study. J Am Coll Cardiol 2008; 51: 1448-54.

[38] Colhoun HM, Betteridge DJ, Durrington PN, et al., and CARDS Investigators. Effects of atorvastatin on kidney outcomes and cardiovascular disease in patients with diabetes: an analysis from the Collaborative Atorvastatin Diabetes Study (CARDS). Am J Kidney Dis 2009; 54: 810-19.

[39] Athyros VG, Karagiannis A, Ganotakis ES, et al. Assessing The Treatment Effect in Metabolic syndrome without Perceptible diabeTes (ATTEMPT) Collaborative Group. Association between the changes in renal function and serum uric acid levels during multifactorial intervention and clinical outcome in patients with metabolic syndrome. A post hoc analysis of the ATTEMPT study. Curr Med Res Opin 2011; 27: 1659-16.

[40] Athyros VG, Giouleme O, Ganotakis ES, et al. Assessing the Treatment Effect in Metabolic syndrome without Perceptible diabeTes (ATTEMPT) Collaborative Group. Safety and impact on cardiovascular events of long-term multifactorial treatment in patients with metabolic syndrome and abnormal liver function tests: a post hoc analysis of the randomised ATTEMPT Study. Arch Med Sci 2011 (in press).

[41] Athyros VG, Kakafika AI, Karagiannis A, Mikhailidis DP. Do we need to consider inflammatory markers when we treat atherosclerotic disease? Atherosclerosis 2008; 200: 1-12.

[42] Solomon DH, Karlson EW, Rimm EB, et al. Cardiovascular morbidity and mortality in women diagnosed with rheumatoid arthritis. Circulation 2003; 107: 1303-7.
[43] Manzi S, Meilahn EN, Rairie JE, et al. Age-specific incidence rates of myocardial infarction and angina in women with systemic lupus erythematosus: comparison with the Framingham Study. Am J Epidemiol 1997; 145: 408-15.

[44] Abou-Raya A, Abou-Raya S. Inflammation: a pivotal link between autoimmune diseases and atherosclerosis. Autoimmun Rev 2006; 5 : $331-7$.

[45] Costenbader KH, Desai A, Alarcón GS, et al. Trends in the incidence, demographics, and outcomes of end-stage renal disease due to lupus nephritis in the US from 1995 to 2006. Arthritis Rheum 2011; 63: 1681-8.

[46] Athyros VG, Kakafika AI, Tziomalos K, Karagiannis A, Mikhailidis DP. Pleiotropic effects of statins--clinical evidence. Curr Pharm Des 2009; 15: 479-89.

[47] Athyros VG, Kakafika AI, Papageorgiou AA, et al. Statin-induced increase in HDL-C and renal function in coronary heart disease patients. Open Cardiovasc Med J 2007; 1: 8-14.

[48] Athyros VG, Katsiki N, Karagiannis N, Mikhailidis DP. Mildly decreased glomerular filtration rate is associated with poor coronary heart disease outcome. Clin Cardiol 2011 (in press).

[49] Athyros VG, Katsiki N, Karagiannis A, Mikhailidis DP. Should chronic kidney disease be considered as a coronary heart disease equivalent? Curr Vasc Pharmacol 2011 (in press).

[50] Reiner Z, Catapano AL, De Backer G, et al. ESC/EAS Guidelines for the management of dyslipidaemias: The Task Force for the management of dyslipidaemias of the European Society of Cardiology (ESC) and the European Atherosclerosis Society (EAS). Eur Heart J 2011; 32: 1769-818.

(C) Athyros et al.; Licensee Bentham Open.

This is an open access article licensed under the terms of the Creative Commons Attribution Non-Commercial License (http://creativecommons.org/licenses/ by-nc/3.0/) which permits unrestricted, non-commercial use, distribution and reproduction in any medium, provided the work is properly cited. 